\title{
PENURUNAN GEOMETRI ELIPSOIDA BUMI
}

\author{
SRI VIONA IRDA \\ Program Studi Matematika, \\ Fakultas Matematika dan Ilmu Pengetahuan Alam, Universitas Andalas, \\ Kampus UNAND Limau Manis Padang, Indonesia, \\ sriviona.irda@yahoo.com
}

\begin{abstract}
Abstrak. Bentuk geoid (bidang ekuipotensial bumi yang dianggap berhimpit dengan permukaan air laut rata-rata) yang tidak beraturan tidak memungkinkan untuk melakukan perhitungan matematis. Oleh karena itu, sebagai representasi matematis dari bentuk fisik bumi, digunakanlah elipsoida. Elipsoida yang digunakan sebagai model bumi sering disebut dengan elipsoida referensi. Pada artikel ini, akan dijelaskan tentang penurunan geometri elipsoida bumi.
\end{abstract}

Kata Kunci: Geometri elipsoida, elipsoida referensi

\section{Pendahuluan}

Bentuk bumi telah menjadi perbincangan sejak lama. Menurut U.S Geological Survey Professional Paper 1395, bumi tidaklah berbentuk bola dan juga tidak sepenuhnya berbentuk elipsoida [3]. Namun, perhitungan matematis mengenai bumi lebih tepat mengasumsikan bumi berbentuk elipsoida. Elipsoida yang digunakan sebagai model bumi sering disebut dengan elipsoida referensi. Pada artikel ini akan dijelaskan tentang penurunan geometri elipsoida bumi.

\section{Geometri Elips dan Elipsoida}

Sebelum membahas elipsoida bumi, akan dijelaskan dulu tentang geometri elips. Elips adalah himpunan titik-titik yang mempunyai jumlah jarak yang konstan terhadap dua titik tetap (disebut titik fokus). Bentuk umum persamaan elips diberikan oleh

$$
\frac{x^{2}}{a^{2}}+\frac{y^{2}}{b^{2}}=1, \quad a, b>0
$$

Berikut dijelaskan penurunan dari persamaan elips (yang sebagian besar bersumber dari [1]).

Perhatikan Gambar 1. Misalkan titik fokus elips tersebut adalah $F=(-c, 0)$ dan $F^{\prime}=(c, 0)$, sehingga $F F^{\prime}=2 c$ dengan $F F^{\prime}$ adalah jarak titik $F$ ke $F^{\prime}$. Ambil sebarang titik pada elips, misalkan titik $H$ dengan koordinat $(x, y)$. Berdasarkan definisi elips, diperoleh

$$
F H+H F^{\prime}=\text { konstan }
$$




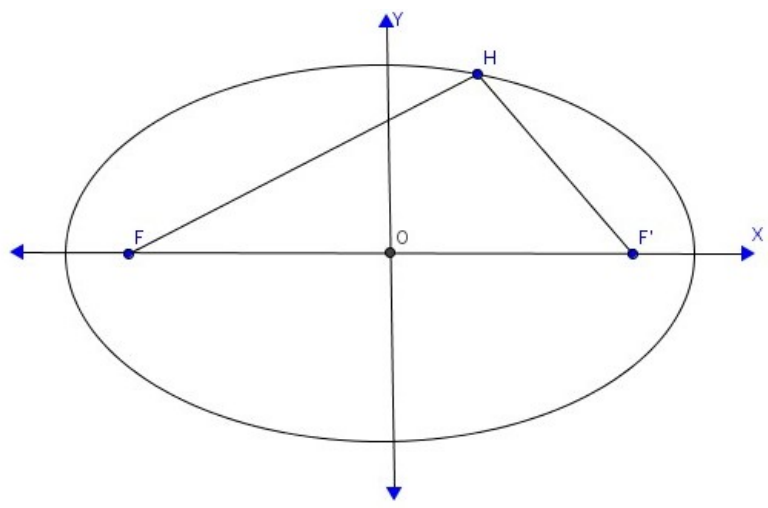

Gambar 1. Contoh elips

Berdasarkan rumus jarak diperoleh

$$
\begin{aligned}
F H & =\sqrt{\left((x-(-c))^{2}+(y-0)^{2}\right.} \\
& =\sqrt{(x+c)^{2}+y^{2}} \\
H F^{\prime} & =\sqrt{(x-c)^{2}+(y-0)^{2}} \\
& =\sqrt{(x-c)^{2}+y^{2}} .
\end{aligned}
$$

Misalkan nilai konstannya adalah $2 a$, maka

$$
F H+H F^{\prime}=2 a \text {. }
$$

Substitusikan (2.2) dan (2.3) ke (2.4), sehingga diperoleh

$$
1=\frac{x^{2}}{a^{2}}+\frac{y^{2}}{a^{2}-c^{2}} .
$$

Perhatikan segitiga $F H F^{\prime}$ pada Gambar 1. Salah satu sisi segitiga tersebut mempunyai panjang $2 c$ yaitu jarak dari $F$ ke $F^{\prime}$, dan jumlah dua sisi lainnya $2 a$. Berdasarkan sifat segitiga, jelas bahwa $2 a>2 c$. Jadi berlaku

$$
a^{2}-c^{2}>0
$$

Karena $a^{2}-c^{2}$ bernilai positif, maka dapat dimisalkan

$$
a^{2}-c^{2}=b^{2}
$$

Dengan demikian persamaan (2.5) menjadi

$$
\frac{x^{2}}{a^{2}}+\frac{y^{2}}{b^{2}}=1 .
$$

Dari persamaan di atas, jelas bahwa titik $( \pm a, 0)$ dan $(0, \pm b)$ berturut-turut adalah titik-titik perpotongan terhadap sumbu- $x$ dan sumbu- $y$. Panjang sumbu- $x$ dan sumbu- $y$ tidaklah sama. Sumbu terpanjangnya disebut dengan sumbu mayor, sedangkan sumbu terpendeknya disebut dengan sumbu minor. Disini $a$ dan $b$ 
berturut-turut dinotasikan sebagai panjang dari setengah sumbu mayor dan setengah sumbu minor dari elips.

Kemudian definisikan eksentriksitas (e) sebagai perbandingan antara jarak dari titik pusat ke titik fokus dengan panjang setengah sumbu mayor elips, yaitu

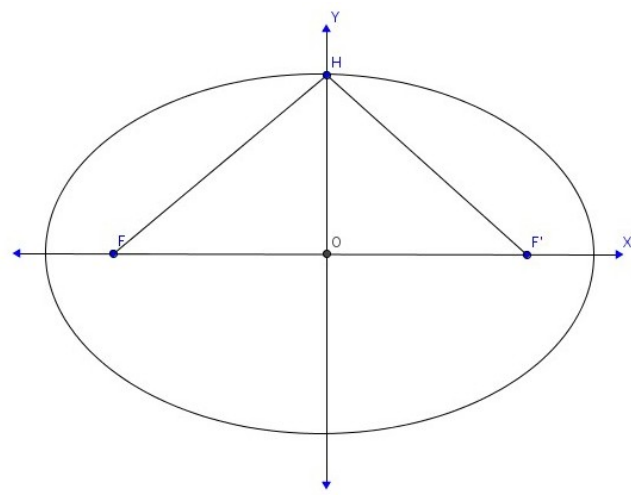

Gambar 2. Elips

$$
e=\frac{c}{a}
$$

Berdasarkan rumus Pythagoras pada segitiga siku-siku $H O F^{\prime}$ (lihat Gambar 2), berlaku

$$
\begin{aligned}
& a^{2}=b^{2}+c^{2} \\
\Leftrightarrow & a^{2}=b^{2}+(a e)^{2} \\
\Leftrightarrow & b^{2}=a^{2}\left(1-e^{2}\right) \\
\Leftrightarrow & \frac{b^{2}}{a^{2}}=\left(1-e^{2}\right) .
\end{aligned}
$$

Selanjutnya definisikan penggepengan $(f)$ sebagai perbandingan antara selisih panjang setengah sumbu mayor dan sumbu minor dengan panjang setengah sumbu mayor, yaitu

$$
f=\frac{a-b}{a} .
$$

Selanjutnya akan dijelaskan penurunan dari persamaan elipsoida. Elipsoida adalah model yang paling representatif untuk bumi. Elipsoida yang digunakan sebagai model bumi sering disebut dengan elipsoida referensi. Berikut dijelaskan penurunan dari persamaan elipsoida (sebagian besar diambil dari [4]).

Perhatikan Gambar 2. Misalkan pada bidang XOY terletak elips dengan persamaan

$$
\left\{\begin{array}{l}
z=0 \\
\frac{x^{2}}{a^{2}}+\frac{y^{2}}{b^{2}}=1,
\end{array}\right.
$$




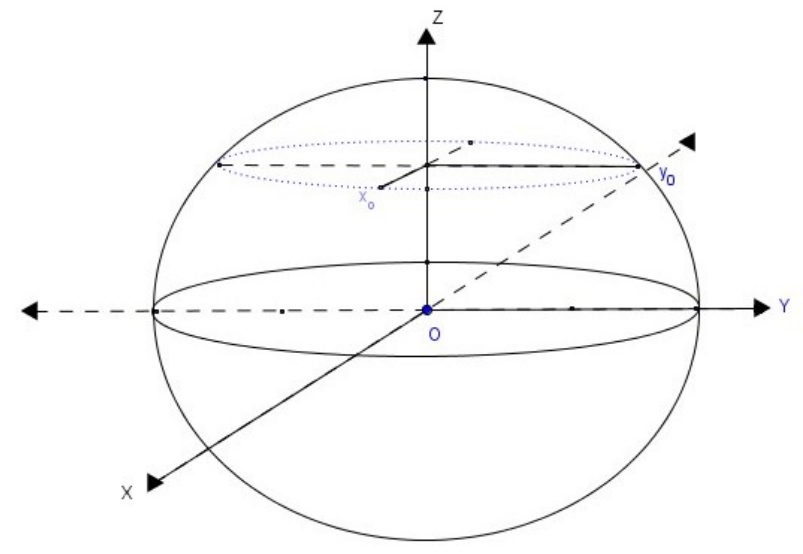

Gambar 3. Contoh elipsoida

dan pada bidang $Y O Z$ terletak elips dengan persamaan

$$
\left\{\begin{array}{l}
x=0 \\
\frac{y^{2}}{b^{2}}+\frac{z^{2}}{c^{2}}=1
\end{array}\right.
$$

Kedua elips di atas mempunyai titik puncak yang sama pada sumbu- $y$.

Selanjutnya diberikan himpunan elips-elips yang dibangun dengan aturan sebagai berikut:

(1) Bidangnya selalu sejajar dengan bidang $X O Y$.

(2) Titik pusatnya tetap pada sumbu- $z$.

(3) Dua dari titik puncaknya selalu terletak pada elips yang terletak pada bidang $Y O Z$.

(4) Sebangun dengan elips yang terletak pada bidang $X O Y$.

Jadi elips pada bidang $Y O Z$ merupakan himpunan titik-titik puncak dari elips yang dibangun dengan aturan-aturan di atas. Himpunan elips-elips tersebut membentuk bangun ruang yang kemudian dinamakan dengan elipsoida. Adapun persamaan elipsoida dapat diturunkan sebagai berikut. Pandang elips yang terletak pada bidang $z=\gamma$ dengan setengah sumbu-sumbunya adalah $x_{0}$ dan $y_{0}$ yang berturut-turut sejajar dengan sumbu- $x$ dan sumbu- $y$. Berdasarkan aturan 1,2 , dan 3 , maka titik $\left(0, y_{0}, \gamma\right)$ terletak pada elips

$$
\left\{\begin{array}{l}
z=0 \\
\frac{y^{2}}{b^{2}}+\frac{z^{2}}{c^{2}}=1,
\end{array}\right.
$$

sehingga memenuhi

$$
\frac{y_{0}^{2}}{b^{2}}+\frac{\gamma^{2}}{c^{2}}=1
$$


atau

$$
y_{0}^{2}=b^{2}\left(1-\frac{\gamma^{2}}{c^{2}}\right) .
$$

Dari aturan 1, 2, dan 4, berlaku

$$
\frac{x_{0}}{y_{0}}=\frac{a}{b}
$$

atau

$$
x_{0}^{2}=\frac{a^{2}}{b^{2}} y_{0}^{2}=\frac{a^{2}}{b^{2}} b^{2}\left(1-\frac{\gamma^{2}}{c^{2}}\right)=a^{2}\left(1-\frac{\gamma^{2}}{c^{2}}\right) .
$$

Jadi persamaan elips yang terletak pada bidang $z=\gamma$ tersebut adalah

$$
\left\{\begin{array}{l}
z=\gamma \\
\frac{x^{2}}{x_{0}^{2}}+\frac{y^{2}}{y_{0}^{2}}=1
\end{array}\right.
$$

atau

$$
\left\{\begin{array}{l}
z=\gamma \\
\frac{x^{2}}{a^{2}\left(1-\frac{\gamma^{2}}{c^{2}}\right)}+\frac{y^{2}}{b^{2}\left(1-\frac{\gamma^{2}}{c^{2}}\right)}=1
\end{array}\right.
$$

Dengan mengeliminasi $\gamma$ pada persamaan (2.8), diperoleh persamaan

$$
\frac{x^{2}}{a^{2}}+\frac{y^{2}}{b^{2}}+\frac{z^{2}}{c^{2}}=1
$$

yang merupakan persamaan elipsoida dengan titik pusat $O$ dan sumbu-sumbunya berimpit dengan sumbu-sumbu koordinat. Jika dua di antara $a, b$, dan $c$ bernilai sama, maka elipsoida tersebut merupakan suatu elipsoida putaran, yaitu elipsoida yang terbentuk dari elips yang diputar $360^{\circ}$ terhadap salah satu sumbunya.

Sistem koordinat elipsoida dinyatakan dalam lintang dan bujur $(\lambda, \varphi)$, dalam hal ini $\lambda$ berkorespondensi dengan sudut bujur bumi, sedangkan $\varphi$ berkorespondensi dengan sudut lintang bumi (lihat Gambar 3). Garis lintang pada elipsoida bumi dapat didefinisikan setidaknya dengan tiga cara yang berbeda [5], yaitu garis lintang geodetik/geografik yang diukur dengan sudut $(\varphi)$; garis lintang geosentrik yang diukur dengan sudut $(\phi)$; dan garis lintang reduksi yang diukur dengan sudut $(\beta)$ (lihat Gambar 3).

Hubungan antara lintang geodetik dengan lintang geosentrik diberikan oleh persamaan

$$
\tan \varphi=\left(\frac{a}{b}\right)^{2} \tan \phi
$$

Perhatikan kembali Gambar 3. Misalkan titik $P$ mempunyai koordinat $(x, y)$. Dengan menotasikan $P T=N$, maka

$$
x=O R=N \cos \varphi .
$$

Selanjutnya $y$ dapat dihitung dengan

$$
y=O R \tan \phi .
$$




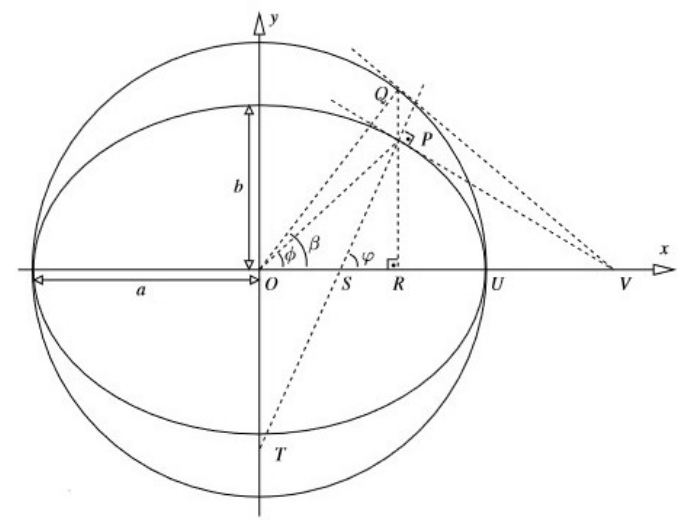

Gambar 4. Meridian elipsoida dan tipe garis lintang

Dengan mensubstitusikan persamaan (2.10), (2.11) dan (2.6) ke persamaan (2.12) diperoleh

$$
\begin{aligned}
P R & =O R \frac{b^{2}}{a^{2}} \tan \varphi \\
& =N\left(1-e^{2}\right) \sin \varphi .
\end{aligned}
$$

Selanjutnya, substitusikan (2.11) dan (2.12) ke persamaan (2.1), sehingga berlaku

$$
\begin{aligned}
\frac{x^{2}}{a^{2}}+\frac{y^{2}}{b^{2}} & =1 \\
\Leftrightarrow \frac{N^{2}}{a^{2}} \cos ^{2} \varphi+\frac{N^{2}\left(1-e^{2}\right)^{2}}{b^{2}} \sin ^{2} \varphi & =1 \\
\Leftrightarrow N & =\frac{a}{\sqrt{1-e^{2} \sin ^{2} \varphi}} .
\end{aligned}
$$

Dalam hal ini $N$ disebut jari-jari kelengkungan vertikal utama.

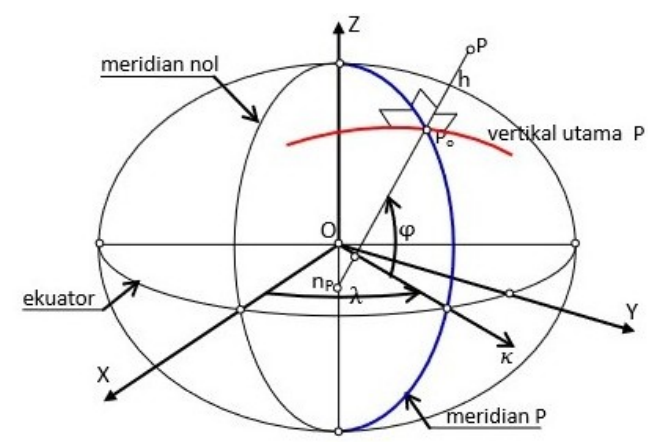

Gambar 5. Sistem koordinat elipsoida

Berikut akan diperlihatkan hubungan antara koordinat elipsoida dengan koordinat kartesius. Perhatikan Gambar 4. Untuk memproyeksikan setiap titik pada 
permukaan elipsoida terhadap sumbu $X, Y$, dan $Z$, diperlukan konversi sistem koordinat elipsoida ke sistem koordinat kartesius. Jika titik yang dikonversikan terletak pada permukaan elipsoida, misalkan titik $P_{0}$, maka diperoleh

$$
\begin{aligned}
X_{P_{0}} & =x \cos \lambda=N_{P_{0}} \cos \varphi \cos \lambda, \\
Y_{P_{0}} & =x \sin \lambda=N_{P_{0}} \cos \varphi \sin \lambda, \\
Z_{P_{0}} & =y=N_{P_{0}}\left(1-e^{2}\right) \sin \varphi,
\end{aligned}
$$

dengan $N_{P_{0}}$ adalah jari-jari kelengkungan vertikal utama di titik $P_{0}\left(n_{P} P_{0}\right)$ (lihat Gambar 4). Nilai $N_{P_{0}}$ dapat ditentukan dari persamaan (2.14).

\section{Model Elipsoida Bumi}

Pandang bumi sebagai elipsoida yang terbentuk dari bidang putar elips, dimana sumbu- $z$ sebagai sumbu putar dengan panjang setengah sumbu mayor adalah $a$ (disebut jari-jari mayor) dan panjang setengah sumbu minor adalah $b$ (disebut jarijari minor). Apabila elipsoida tersebut pusatnya terletak pada titik asal di $\mathbb{R}^{3}$, maka dapat ditulis persamaannya dalam koordinat kartesius sebagai berikut:

$$
S_{R}=\left\{(x, y, z) \mid \frac{x^{2}+y^{2}}{a^{2}}+\frac{z^{2}}{b^{2}}=1, a, b>0\right\} .
$$

Hubungan antara koordinat elipsoida dengan koordinat kartesius diberikan oleh

$$
\begin{aligned}
& X=N \cos \varphi \cos \lambda, \\
& Y=N \cos \varphi \sin \lambda, \\
& Z=N\left(1-e^{2}\right) \sin \varphi,
\end{aligned}
$$

dengan $0 \leq \lambda \leq 2 \pi, 0 \leq \varphi \leq \pi, N$ adalah jari-jari kelengkungan vertikal utama, dan $e$ adalah eksentriksitas.

Pada sistem elipsoida referensi WGS84 [2], panjang jari-jari mayor bumi adalah $a=6378137 \mathrm{~m}$ dan penggepengan (flattening) $f=1 / 298.257223563$. Kemudian dengan menggunakan persamaan (2.7), diperoleh panjang jari-jari minor bumi adalah $b=a(1-f) \approx 6356800 \mathrm{~m}$.

Untuk menentukan posisi suatu tempat secara tepat di permukaan bumi, biasanya digunakan garis geografi yang diakui secara internasional, yaitu garis lintang dan garis bujur. Garis lintang dan garis bujur yang tepat berada pada $0^{0}$ berturut-turut disebut dengan garis ekuator $\left(\varphi=0^{0}\right)$ dan garis Greenwich $\left(\lambda=0^{0}\right)$. Menurut penamaannya, kelompok garis lintang yang berada di sebelah utara dan selatan ekuator berturut-turut disebut dengan Lintang Utara (LU) dan Lintang Selatan (LS), sedangkan kelompok garis bujur yang berada di sebelah timur dan barat garis Greenwich berturut-turut disebut dengan Bujur Timur (BT) dan Bujur Barat (BB). Masing-masing garis (lintang dan bujur) ditentukan secara tunggal oleh besaran sudut. Jadi, dalam koordinat elipsoida dapat ditulis

$$
\varphi=\left\{\begin{array}{l}
p, p \in L U, \\
-p, p \in L S,
\end{array}\right.
$$


dan

$$
\lambda=\left\{\begin{array}{l}
q, q \in B T, \\
-q, q \in B B .
\end{array}\right.
$$

\section{Kesimpulan}

Konversi sistem koordinat elipsoida bumi ke sistem koordinat kartesius diberikan oleh hubungan berikut:

$$
\begin{aligned}
& X=N \cos \varphi \cos \lambda, \\
& Y=N \cos \varphi \sin \lambda, \\
& Z=N\left(1-e^{2}\right) \sin \varphi,
\end{aligned}
$$

dimana $\varphi_{B}$ dan $\lambda_{B}$ berkorespondensi dengan koordinat lintang $(p)$ dan bujur $(q)$ dengan ketentuan

$$
\varphi_{B}=\left\{\begin{array}{l}
p, p \in L U, \\
-p, p \in L S,
\end{array}\right.
$$

dan

$$
\lambda_{B}=\left\{\begin{array}{l}
q, q \in B T, \\
-q, q \in B B,
\end{array}\right.
$$

sedangkan $N$ dan $e$ berturut-turut menyatakan jari-jari kelengkungan vertikal utama dan eksentriksitas.

\section{Ucapan Terima Kasih}

Penulis mengucapkan terima kasih kepada Bapak Dr. Mahdhivan Syafwan, Bapak Zulakmal, M.Si, Bapak Narwen, M.Si, Ibu Nova Noliza Bakar, M.Si dan Ibu Radhiatul Husna, M.Si yang telah memberikan masukan dan saran sehingga paper ini dapat diselesaikan dengan baik.

\section{Daftar Pustaka}

[1] Anonim. 2010. BAB V Ellips. http://toermoedy.files.wordpress.com, diakses pada tanggal 2 Juni 2015.

[2] Jekeli C. 2006. Geometric Reference Systems in Geodesy. http://kb.osu/dspace/ bitstream/Geometric.Reference.Systems2012.pdf, diakses pada tanggal 17 April 2015.

[3] Noordin N., Ishak S.N., dan Ali J.M. 2012. Deviation of Qibla Direction. Discovering Mathematics. Vol.34 (1): 57-62.

[4] Susanto. 2012. Geometri Analitik Ruang. https://library.unej.ac.id, diakses pada tanggal 2 Juni 2015.

[5] Vermeer, Martin. 2015. Mathematical Geodesy Ma-6.3230.https://users.aalto. fi/mvermeer/geomen.pdf, diakses pada tanggal 2 Juni 2015. 